\title{
Comparison of estrone and $17 \beta$-estradiol levels in commercial goat and cow milk ${ }^{1}$
}

\author{
D. W. Farlow, X. Xu, and T. D. Veenstra ${ }^{2}$ \\ Laboratory of Proteomics and Analytical Technologies, Advanced Technology Program, SAIC-Frederick Inc., NCI-Frederick, Frederick, MD 21702
}

\section{ABSTRACT}

Increased levels of estrogen metabolites are believed to be associated with cancers of the reproductive system. One potential dietary source of these metabolites that is commonly consumed worldwide is milk. In North America, dairy cows are the most common source of milk; however, goats are the primary source of milk worldwide. In this study, the absolute concentrations of unconjugated and total (unconjugated plus conjugated) estrone $\left(\mathrm{E}_{1}\right)$ and $17 \beta$-estradiol $\left(\mathrm{E}_{2}\right)$ were compared in a variety of commercial cow milks (regular and organic) and goat milk. A lower combined concentration of $\mathrm{E}_{1}$ and $\mathrm{E}_{2}$ was found in goat milk than in any of the cow milk products tested. The differences in $\mathrm{E}_{1}$ and $\mathrm{E}_{2}$ levels between regular and organic cow milks were not as significant as the differences between goat milk and any of the cow milk products. Goat milk represents a better dietary choice for individuals concerned with limiting their estrogen intake.

Key words: goat milk, cow milk, estrone, 17ß-estradiol

\section{INTRODUCTION}

Although cow milk is the most consumed milk in North America, several studies indicate that goat milk is the most ingested milk globally (Haenlein, 2001). The nutritional and medical benefits of goat milk have been widely acknowledged, but little unbiased medical research has been conducted and the physiological and biochemical properties of goat milk are barely known (Haenlein, 2004). Given the expressed need for further research regarding milk consumption and increased cancer risk, it is imperative to further explore milk products that are consumed on a regular basis, particularly goat milk, given its worldwide prevalence (Willett,

\footnotetext{
Received October 21, 2011.

Accepted November 17, 2011.

${ }^{1}$ The content of this publication does not necessarily reflect the views or policies of the Department of Health and Human Services, nor does mention of trade names, commercial products, or organization imply endorsement by the United States Government.

${ }^{2}$ Corresponding author: veenstra@ncifcrf.gov
}

2003; Larsson et al., 2004; Courant et al., 2008). Moreover, the need to directly compare goat and cow milk to better understand the benefits and limitations of each has been expressed by the Dairy Research and Information Center (http://drinc.ucdavis.edu/goat1.htm).

The popularity of using goats as a dairy source has risen in recent years because they require minimal land use. In addition, goats are often maintained on pasture that would otherwise be inaccessible to other dairy animals with no decrease in the nutritive value of their milk (Larsson et al., 2004). Even though there are obvious benefits to their use as dairy animals, the goat milk industry has not flourished in the United States, a truth made evident by the fact that goat milk is largely sold in specialty stores or purchased directly from the farmer. Part of the reason lies in the fact that most small dairymen have great difficulty with meeting government sanitation standards for commercial products. In spite of these difficulties, the top producers of commercially available goat milk in the United States have increased production more than $30 \%$ to keep up with demand. This increased demand is likely due to the growing ethnic diversity in the United States today; consequently, it is expected that the goat industry will continue to expand as long as the ethnic population continues to grow.

The literature suggests that goat milk has higher nutritional value than cow milk. Goat milk has higher concentrations of phosphorous, potassium, vitamin A, and calcium; cow milk does, however, have a higher concentration of folate (Willett et al., 2003; Qin et al., 2004; Courant et al., 2008). Although conventional thought suggests that cow milk is the best source of calcium, goat milk actually provides more calcium per serving (Willett, 2003; Courant et al., 2008). Cow milk supplies approximately $276 \mathrm{mg}$ of calcium per cup compared with $327 \mathrm{mg}$ per cup for goat milk (Qin et al., 2004). Although this $19 \%$ increase in calcium content may be small, it may be an important factor for growing children and individuals suffering from osteoporosis.

Allergic reactions to cow milk proteins have become increasingly common (Dias et al., 2010). Many allergies are related to the protein casein $\alpha \mathrm{S} 1$, which is a found in higher concentration in cow milk than in goat milk 
(Savilahti et al., 2010). Lactalbumin, which can also provoke allergic reactions, specifically in small children, is not present in goat milk (Solinas et al., 2010). The presence of simpler, smaller proteins and fat molecules is considered to be one of the primary reasons why goat milk is easier to digest than cow milk (Coila, 2010). Another possible reason for easier digestion may be that the fat globules in goat milk do not cluster due to the lack of the protein agglutinin, which is found in cow milk (http://fiascofarm.com/dairy/rawmilk.htm).

The largest health concern for consumers of goat milk is likely to be its elevated fat content compared with cow milk. Whereas goat milk has $10.1 \mathrm{~g}$ of fat per a single cup serving, cow milk contains $7.9 \mathrm{~g}$ (Liehr, 2000; Ganmaa and Sato, 2005). More troubling for consumers, perhaps, is how much of the fat content in goat milk is composed of saturated fat. Goat milk has 6.5 $\mathrm{g}$ of saturated fat per cup compared with $5.0 \mathrm{~g}$ in cow milk. Despite its higher content, the fat in goat milk is easier to digest than that found in cow milk due to the fact that more of the fat is made of short- and mediumchain fatty acids. However, because low-fat and non-fat varieties of goat milk are hard to find commercially, if one is looking to have a heart-healthy diet that includes dairy, the literature suggests goat milk may not be the best alternative to cow milk.

Due to the lower lactose quantities of goat milk (4.1\%) compared with cow milk $(4.7 \%)$, research indicates that goat milk may be more easily digested and tolerated by individuals who are slightly or mildly lactose intolerant. Even the slightly lower lactose levels, however, are not enough to make goat milk consumable by individuals who are fully lactose intolerant (Bernstein and Ross, 1993).

One group of functional molecules that have not been widely compared within the dairy industry is steroid hormones, in particular estrogens. According to numerous epidemiological studies in recent decades, estrogens are now considered to be risk factors for cancer, particularly in the breasts, ovaries, and prostate (Chen et al., 2006; Yager and Davidson, 2006). Given that milk and dairy intake account for 60 to $70 \%$ of total estrogen consumption, it is important to investigate commercially available milk products to better understand whether they pose a risk factor for cancer (Ganmaa and Sato, 2005; Farlow et al., 2009).

\section{MATERIALS AND METHODS}

\section{Reagents and Materials}

Estrone $\left(\mathbf{E}_{1}\right)$ and $17 \beta$-estradiol $\left(\mathbf{E}_{\mathbf{2}}\right)$ standards were obtained from Steraloids Inc. (Newport, RI). The stable isotope-labeled estrogens, estradiol-13,14,15,16,17,18${ }^{13} \mathrm{C}_{6} \quad\left({ }^{13} \mathrm{C}_{6}-\mathrm{E}_{2}\right)$ and estrone- $13,14,15,16,17,18-{ }^{13} \mathrm{C}_{6}$ $\left({ }^{13} \mathrm{C}_{6}-\mathrm{E}_{1}\right)$, were purchased from Cambridge Isotope Laboratories Inc. (Andover, $\mathrm{MA}$ ). Both $\mathrm{E}_{1}$ and $\mathrm{E}_{2}$ were used without further purification and have reported chemical and isotopic purities $\geq 98 \%$. Dichloromethane, methanol, and formic acid were obtained from EM Science (Gibbstown, NJ). Glacial acetic acid, sodium bicarbonate, and L-ascorbic acid were purchased from J. T. Baker Inc. (Phillipsburg, NJ). Sodium hydroxide and sodium acetate were purchased from Fisher Scientific Co. LLC (Fair Lawn, NJ). $\beta$-Glucuronidase/sulfatase (Helix pomatia, Type HP-2) was obtained from Sigma Chemical Co. (St. Louis, MO). Dansyl chloride and acetone were purchased from Aldrich Chemical Co. (Milwaukee, WI). All chemicals and solvents used in this study were HPLC or reagent grade.

\section{Milk Samples}

Seven milk samples were collected for this study: whole milk, $2 \%$ milk, nonfat milk, organic whole milk, organic $2 \%$ milk, organic nonfat milk, and regular goat milk. All milk samples are assumed to be from cows unless otherwise indicated. The cow milks were produced by Bloom (Salisbury, NC) and purchased at a local grocery store (Bloom, Frederick, MD). The goat milks were purchased at MOM's Organic Market (Frederick, $\mathrm{MD})$. Milk was aliquoted and stored at $-40^{\circ} \mathrm{C}$ until analyzed. Each sample was analyzed in triplicate in 4 separate batches, yielding a total of 12 analyses for each milk product.

\section{Preparation of Stock and Working Standard Solutions}

Stock solutions of $\mathrm{E}_{1}$ and $\mathrm{E}_{2}$ were prepared at a concentration of $80 \mu \mathrm{g} / \mathrm{mL}$ by dissolving $2 \mathrm{mg}$ of each steroid hormone in $25 \mathrm{~mL}$ of methanol containing $0.1 \%$ (wt/vol) L-ascorbic acid. Time-dependent degradation of the standards within the stock solutions was monitored by measuring the absolute peak height of $\mathrm{E}_{1}$ and $\mathrm{E}_{2}$ using capillary liquid chromatography-tandem mass spectrometry (LC-MS/MS). No degradation was observed for these solutions stored at least 2 mo at $-20^{\circ} \mathrm{C}$. Working standard solutions of $\mathrm{E}_{1}$ and $\mathrm{E}_{2}$ (as well as the stable isotope-labeled versions of these steroid hormones) having a concentration of $8 \mathrm{ng} / \mathrm{mL}$ were prepared by diluting the stock solutions with methanol containing $0.1 \%$ (wt/vol) L-ascorbic acid.

\section{Calibration Standards}

Milk fortified with $0.1 \%$ (wt/vol) L-ascorbic acid and having no detectable levels of estrogen metabolites 
was used for preparation of calibration standards and quality control samples. Calibration standards were prepared by adding $20 \mu \mathrm{L}$ of the stable isotope working internal standard $(\mathbf{S I})$ solution $\left(0.16 \mathrm{ng}\right.$ of $\mathrm{SI}_{-} \mathrm{E}_{1}$ or $\mathrm{E}_{2}$ ) to various volumes of working standard solution, which typically contained 0.002 to $2 \mathrm{ng}$ of each metabolite. Each calibration standard was assayed in duplicate. Quality control samples were prepared containing 8, 40 , and $160 \mathrm{pg} / \mathrm{mL}(26.5-29.6,132.4-148.0$, and 529.5$592.2 \mathrm{fmol} / \mathrm{mL}$ ) of $\mathrm{E}_{1}$ and $\mathrm{E}_{2}$. The accuracy (measured as the percent matching of calculated amount to known amount of $E_{1}$ and $E_{2}$ in control samples) and precision (measured as the percent relative standard deviations) of the quality control samples are provided in Table 1 . Calibration curves generated for $\mathrm{E}_{1}$ and $\mathrm{E}_{2}$ are provided in Figure 1. These calibration curves were linear over a $10^{3}$-fold range ( 0.2 to $200 \mathrm{pg}$ on column) with coefficient of determination greater than 0.998 .

\section{Sample Preparation}

The methods used to prepare the samples (Xu et al., 2005, 2007a; Farlow et al., 2009) were designed to specifically target the following: 1) biologically active, unconjugated parent $\mathrm{E}_{1}$ and $\mathrm{E}_{2}$ and 2) total (biologically active plus their sulfate or glucuronide conjugates, or both) levels of $E_{1}$ and $E_{2}$. For measuring total milk $\mathrm{E}_{1}$ and $\mathrm{E}_{2}$ levels $(\mathbf{E M}), 20 \mu \mathrm{L}$ of the stable isotope containing working internal standard solution $(0.16 \mathrm{ng}$ of SI-EM) was added to a 2-mL aliquot of milk, followed by addition of $7 \mathrm{~mL}$ of methanol. After $30 \mathrm{~min}$ of inverse extraction, the sample was centrifuged at $2,500 \times g$ for $30 \mathrm{~min}$. The supernatant was transferred to a clean screw-capped glass tube, and the methanol evaporated by heating at $60^{\circ} \mathrm{C}$ (Reacti-Vap III; Pierce Biotechnology Inc., Rockford, IL) under a stream of $\mathrm{N}_{2}$ gas. Freshly prepared enzymatic hydrolysis buffer $(0.5 \mathrm{~mL})$ containing $5 \mathrm{mg}$ of L-ascorbic acid, $15 \mu \mathrm{L}$ of $\beta$-glucuronidase/sulfatase, and $1.5 \mathrm{~mL}$ of $0.15 \mathrm{M}$ sodium acetate buffer ( $\mathrm{pH} 4.6$ ) was prepared as described previously. After sulfatase and glucuronidase hydrolysis by incubation for $20 \mathrm{~h}$ at $37^{\circ} \mathrm{C}, 8 \mathrm{~mL}$ of dichloromethane was added and the samples underwent slow inverse
A)

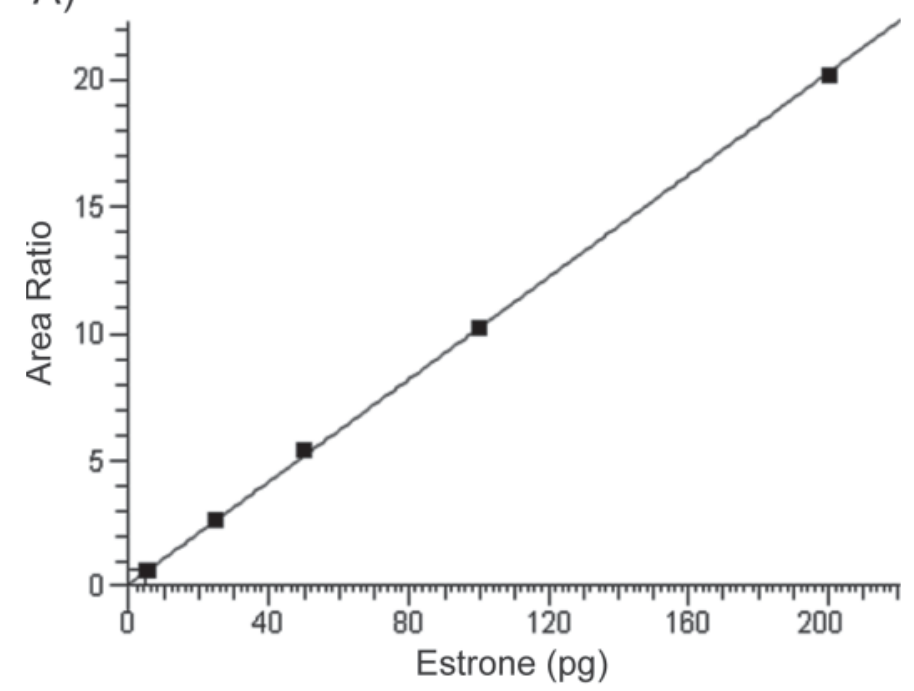

B)

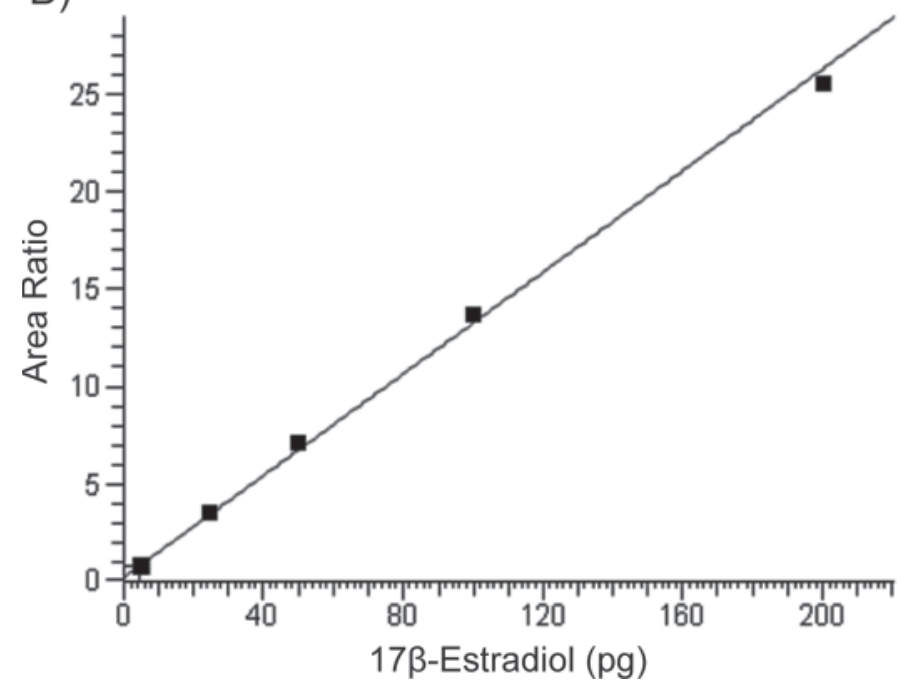

Figure 1. Calibration curves for A) estrone and B) 17 $\beta$-estradiol measured in the various milk products tested.

extraction at $8 \mathrm{rpm}$ (RKVSD; ATR Inc., Laurel, MD) for $30 \mathrm{~min}$. After extraction, the organic solvent portion was transferred into a clean glass tube and evaporated

Table 1. Accuracy and precision $(\%)^{1}$ of measurements of quality control samples for estrogen measurements

\begin{tabular}{lccccccc}
\hline & \multicolumn{3}{c}{ Accuracy } & & \multicolumn{3}{c}{ Precision } \\
\cline { 2 - 4 } \cline { 6 - 8 } Item & $80 \mathrm{pg} / \mathrm{mL}$ & $40 \mathrm{pg} / \mathrm{mL}$ & $160 \mathrm{pg} / \mathrm{mL}$ & & $80 \mathrm{pg} / \mathrm{mL}$ & $40 \mathrm{pg} / \mathrm{mL}$ & $160 \mathrm{pg} / \mathrm{mL}$ \\
\hline $\mathrm{E}_{1}$ & 101.5 & 101.9 & 100.5 & & 7.09 & 5.95 & 4.30 \\
$\mathrm{E}_{2}$ & 97.2 & 99.8 & 98.9 & & 6.39 & 3.30 & 2.94 \\
\hline
\end{tabular}

${ }^{1}$ Accuracy was measured as the percent matching of the calculated amount to known amount of milk estrone $\left(\mathrm{E}_{1}\right)$ and $17 \beta$-estradiol $\left(\mathrm{E}_{2}\right)$ in control samples. Precision was measured as the percent relative standard deviation. 
to dryness at $60^{\circ} \mathrm{C}$ under $\mathrm{N}_{2}$ gas (Reacti-Vap III; Pierce Biotechnology Inc.). To the dried sample, $100 \mu \mathrm{L}$ of 0.1 $M$ sodium bicarbonate buffer ( $\mathrm{pH}$ at 9.0) and $100 \mu \mathrm{L}$ of dansyl chloride solution $(1 \mathrm{mg} / \mathrm{mL}$ in acetone) were added. The sample was vortexed and heated at $60^{\circ} \mathrm{C}$ (Reacti-Therm III Heating Module; Pierce Biotechnology Inc.) for 5 min to produce the $\mathrm{E}_{1}$ and $\mathrm{E}_{2}$ and stable isotope-labeled $\mathrm{E}_{1}$ and $\mathrm{E}_{2}$ dansyl derivatives ( $\mathrm{E}_{1}$-dansyl, $\mathrm{E}_{2}$-dansyl, SI-E $\mathrm{E}_{1}$-dansyl, and $\mathrm{SI}-\mathrm{E}_{2}$-dansyl, respectively). Calibration standards were hydrolyzed, extracted, and derivatized following the same procedure. After derivatization, all samples were analyzed by LC-MS/ MS. For the measurement of total (unconjugated plus conjugated) $\mathrm{E}_{1}$ and $\mathrm{E}_{2}$ levels, identical sample preparation was used with the omission of the $\beta$-glucuronidase/ sulfatase hydrolysis step.

\section{Capillary LC-MS/MS Analysis}

Quantitative analysis was performed using an Agilent 1200 Series Nanoflow LC system (Agilent Technologies Inc., Palo Alto, CA) coupled to a TSQ Quantum Ultra triple quadrupole mass spectrometer (Thermo Electron Corp., San Jose, CA). The LC separation was conducted using a $150-\mathrm{mm}$ long $\times 300-\mu \mathrm{m}$ i.d. column packed with $4 \mu \mathrm{m}$ of Synergi Hydro-RP particles (Phenomenex Inc., Torrance, CA), maintained at $40^{\circ} \mathrm{C}$. A total of 8 $\mu \mathrm{L}$ of each sample was injected onto the column. The mobile phases consisted of methanol as solvent A and $0.1 \%$ (vol/vol) formic acid in water as solvent B. A linear gradient from 72 to $85 \%$ solvent B in 75 min, at a flow rate of $4 \mu \mathrm{L} / \mathrm{min}$, was used for separation of $\mathrm{E}_{1}$ and $\mathrm{E}_{2}$. The MS conditions were as follows: source: ESI; ion polarity: positive; spray voltage: $3,500 \mathrm{~V}$; sheath and auxiliary gas: nitrogen; sheath gas pressure: 7 arbitrary units; ion transfer capillary temperature: $270^{\circ} \mathrm{C}$; scan type: selected reaction monitoring; collision gas: argon; collision gas pressure: $0.2 \mathrm{~Pa}$; scan width: 0.7 unit resolution $(\mathrm{u})$; scan time: $0.50 \mathrm{~s}$; Q1 peak width: 0.70 $\mathrm{u}$ full-width half-maximum (FWHM); Q3 peak width: $0.70 \mathrm{u}$ FWHM. The optimized selected reaction monitoring conditions for the protonated molecules $\left[\mathrm{M}^{+} \mathrm{H}^{+}\right]$ of EM-dansyl and SI-EM-dansyl were similar to those described previously [23,24; thus, a charge state of 1$]$. Briefly, $\mathrm{E}_{1} \mathrm{~m} / z \quad 504 \rightarrow 171$ collision energy: $32 \mathrm{eV} ; \mathrm{E}_{2}$ $m / z 506 \rightarrow 171$ collision energy: $35 \mathrm{eV}$.

\section{Quantitation of Estrone and 17 $\beta$-Estradiol}

Quantitation of $\mathrm{E}_{1}$ and $\mathrm{E}_{2}$ was carried out using Xcalibur Quan Browser (Thermo Finnigan Corp., San Jose, CA). Calibration curves for each metabolite were constructed by plotting $\mathrm{E}_{1}$-dansyl/SI- $\mathrm{E}_{1}$-dansyl and $\mathrm{E}_{2}$-dansyl/SI- $\mathrm{E}_{2}$-dansyl peak area ratios obtained from calibration standards versus amounts of each steroid hormone and fitting these data using linear regression with $1 / X$ weighting. The amount of $\mathrm{E}_{1}$ and $\mathrm{E}_{2}$ in milk samples was interpolated using this linear function. Based on their similarity of structures and retention times, ${ }^{13} \mathrm{C}_{6}-\mathrm{E}_{1}$ and ${ }^{13} \mathrm{C}_{6}-\mathrm{E}_{2}$ were used as the internal standards for $\mathrm{E}_{1}$ and $\mathrm{E}_{2}$.

\section{RESULTS}

In this study, the levels of unconjugated and total (unconjugated + conjugated) $\mathrm{E}_{1}$ and $\mathrm{E}_{2}$ were measured in a variety of commercially available cow and goat milk products. Unconjugated refers to the free, biologically active forms of these steroid hormones, whereas total includes both the unconjugated and conjugated levels. To measure the total levels, the conjugated forms of $\mathrm{E}_{1}$ and $\mathrm{E}_{2}$ (i.e., sulfated and glucuronidated) are converted to the unconjugated forms by treating the samples with a sulfatase/glucuronidase enzyme before LC-MS/MS analysis. Representative chromatograms showing the detection of unconjugated $\mathrm{E}_{1}$ and $\mathrm{E}_{2}$ in the milk products analyzed in this study are shown in Figures $2 \mathrm{~A}$ and B, respectively. Although comparisons between the levels of these steroid hormones cannot be made directly from these figures, they do illustrate the excellent signal-to-noise ratio that was observed in the measurements. Representative chromatograms showing the detection of total (unconjugated + conjugated) $\mathrm{E}_{1}$ and $\mathrm{E}_{2}$ in the milk products analyzed in this study are shown in Figure 3A and B, respectively. The signalto-noise ratio of these chromatograms was significantly higher than that of their respective counterparts in Figure 2, indicating that $\mathrm{E}_{1}$ and $\mathrm{E}_{2}$ exist in milk primarily in their conjugated forms.

The absolute concentrations of unconjugated $\mathrm{E}_{1}$ and $\mathrm{E}_{2}$ detected in this study for all commercially available milk forms are shown in Figure 4A and listed in Table 2 (mean \pm standard deviation of 12 samples). Regular whole $(14.45 \mathrm{pg} / \mathrm{mL})$ and regular $2 \%$ (13.58 $\mathrm{pg} / \mathrm{mL}$ ) cow milks contain the highest concentrations of unconjugated $\mathrm{E}_{1}$. Goat milk contains the lowest concentration of biologically active $\mathrm{E}_{1}(1.45 \mathrm{pg} / \mathrm{mL})$. The concentration of $\mathrm{E}_{1}$ in goat milk was more than 3 -fold less than that found in any of the other milk products tested. The highest concentrations of biologically active $\mathrm{E}_{2}$ were found in organic $(6.00 \mathrm{pg} / \mathrm{mL})$ and regular whole $(5.84 \mathrm{pg} / \mathrm{mL})$ cow milks. Whereas goat milk contained $1.82 \mathrm{pg} / \mathrm{mL}$, the lowest unconjugated $\mathrm{E}_{2}$ levels were found in organic nonfat $(0.48 \mathrm{pg} / \mathrm{mL})$ and regular nonfat $(0.63 \mathrm{pg} / \mathrm{mL})$ milks.

The sum of the unconjugated concentrations of $\mathrm{E}_{1}$ and $\mathrm{E}_{2}$ were significantly lower in goat milk $(3.27 \mathrm{pg} /$ $\mathrm{mL}$ ) than any of the other milks tested (Table 2). This 
A)
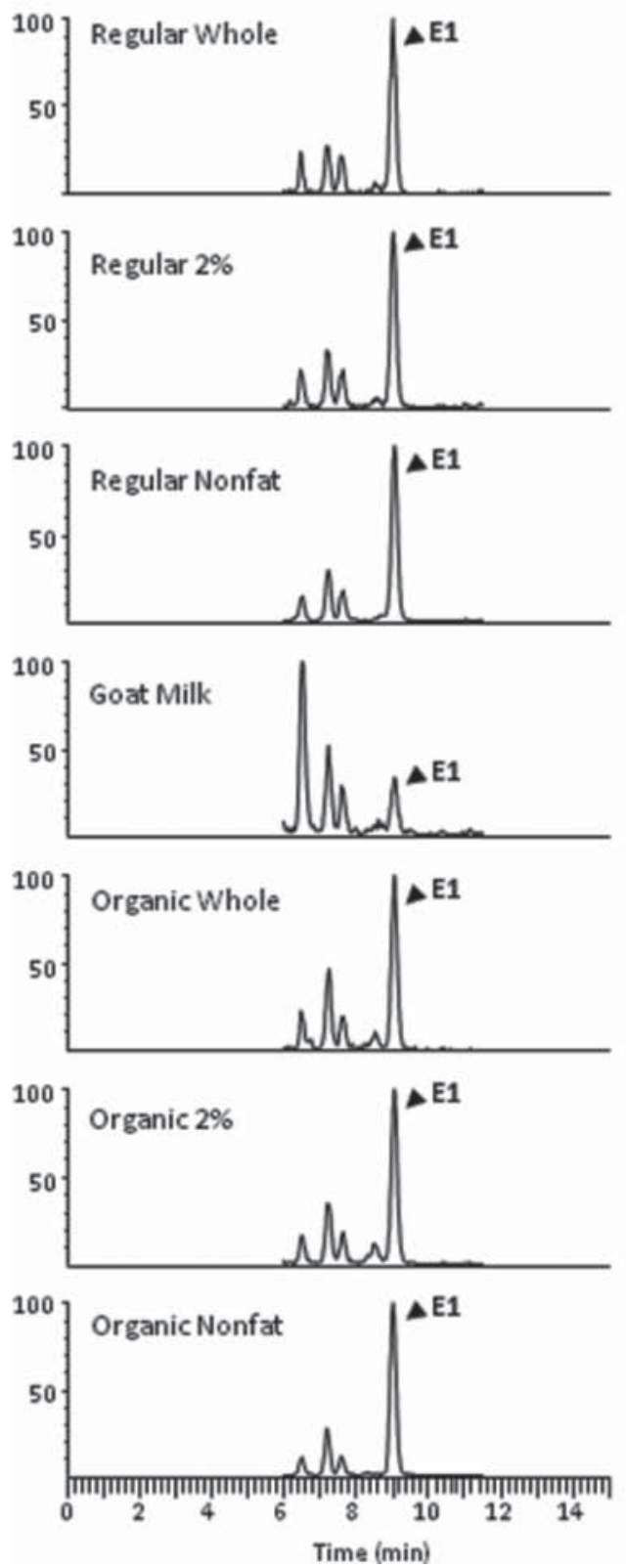

B)
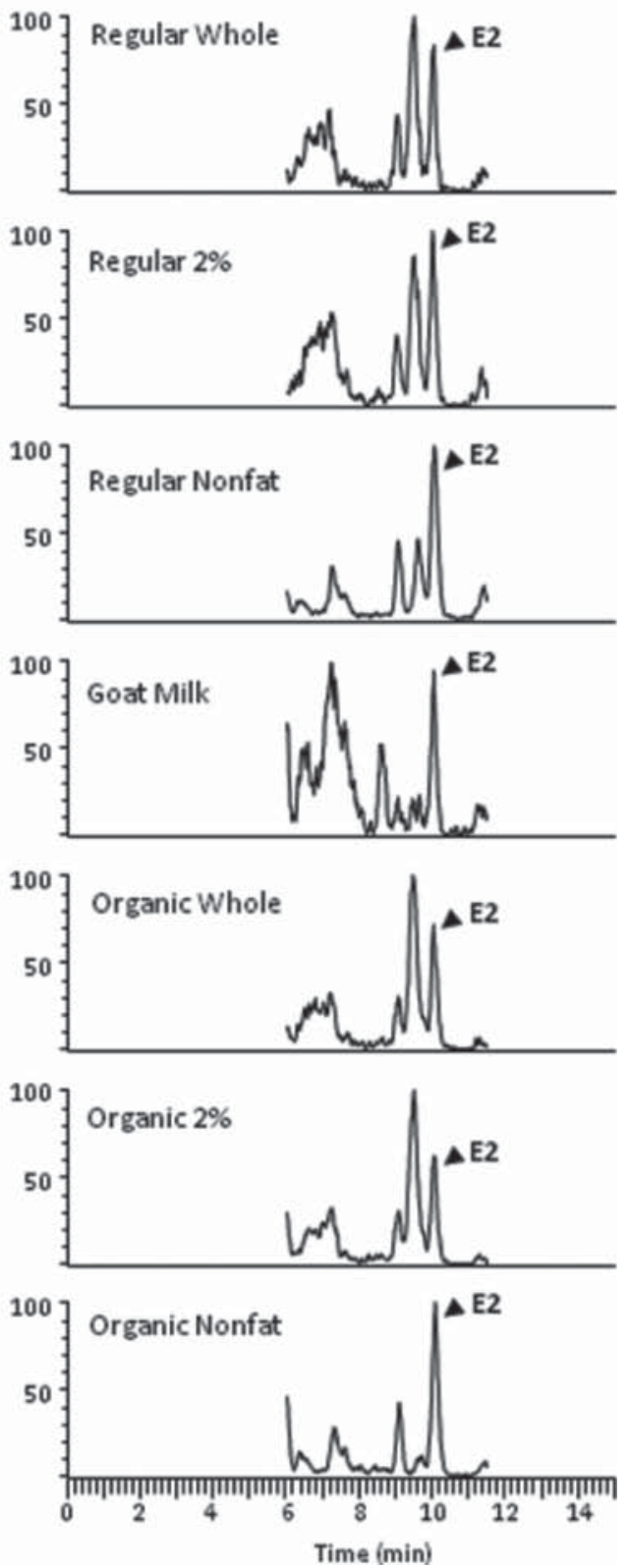

Figure 2. High performance liquid chromatography-tandem mass spectrometry selected reaction monitoring (SRM) chromatographic profiles of $\mathrm{A}$ ) unconjugated estrone $\left(\mathrm{E}_{1}\right)$ and $\left.\mathrm{B}\right) 17 \beta$-estradiol $\left(\mathrm{E}_{2}\right)$ in all milk forms analyzed in this study.

concentration was only $16 \%$ of that found in regular whole milk, which contained the highest accumulative concentration of $\mathrm{E}_{1}$ and $\mathrm{E}_{2}$. The sum of the unconjugated concentration of $\mathrm{E}_{1}$ and $\mathrm{E}_{2}$ was 1.75 - and 1.49fold higher in regular nonfat and organic nonfat milk compared with goat milk, respectively. These results show that goat milk contains a substantially lower concentration of unconjugated $\mathrm{E}_{1}$ and $\mathrm{E}_{2}$ levels compared with any of the varieties of cow milks that were tested.
The total (unconjugated + conjugated) concentrations of both steroid hormones in each milk product are shown in Table 3 and Figure 4B. As with the unconjugated levels, the absolute concentrations of total $\mathrm{E}_{1}$ and $\mathrm{E}_{2}$ detected in this study for all commercially available milk forms are provided as data expressed as mean \pm standard deviation of 12 samples. Overall, the data indicate that $\mathrm{E}_{1}$ and $\mathrm{E}_{2}$ exist in milk primarily in their various conjugated forms (i.e., glucuronidated and 

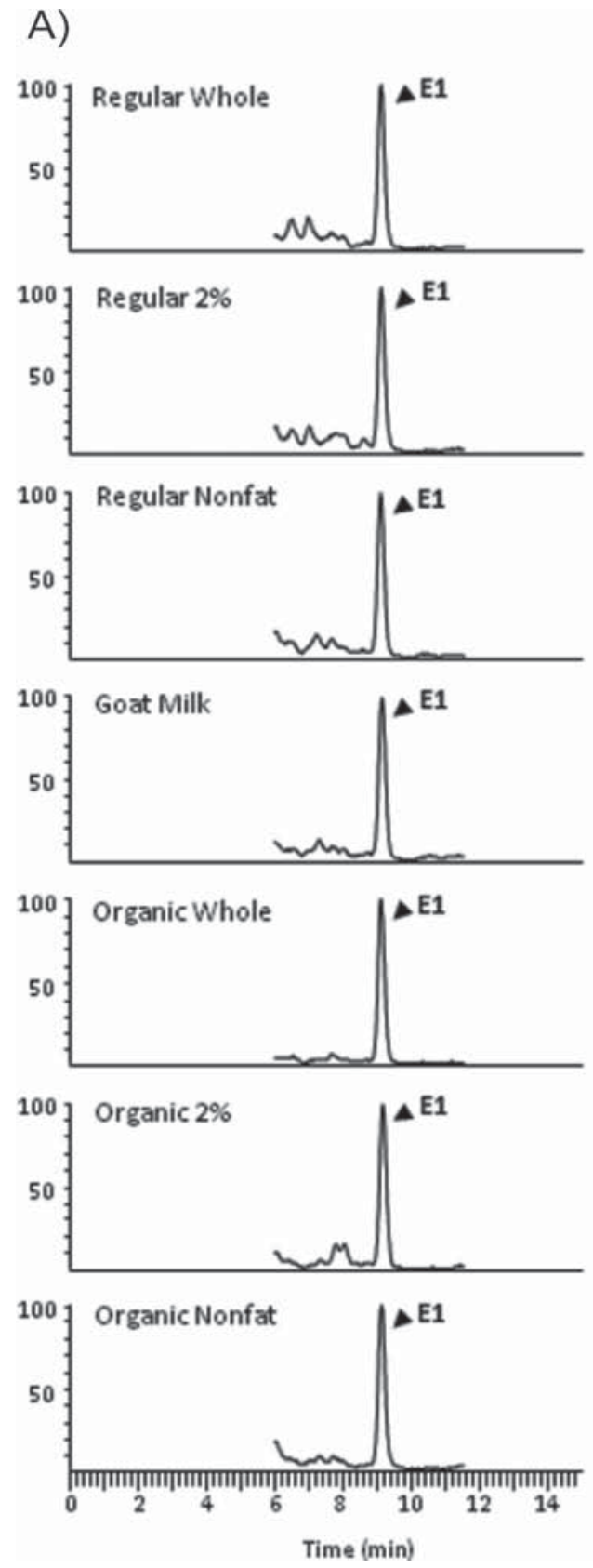

B)
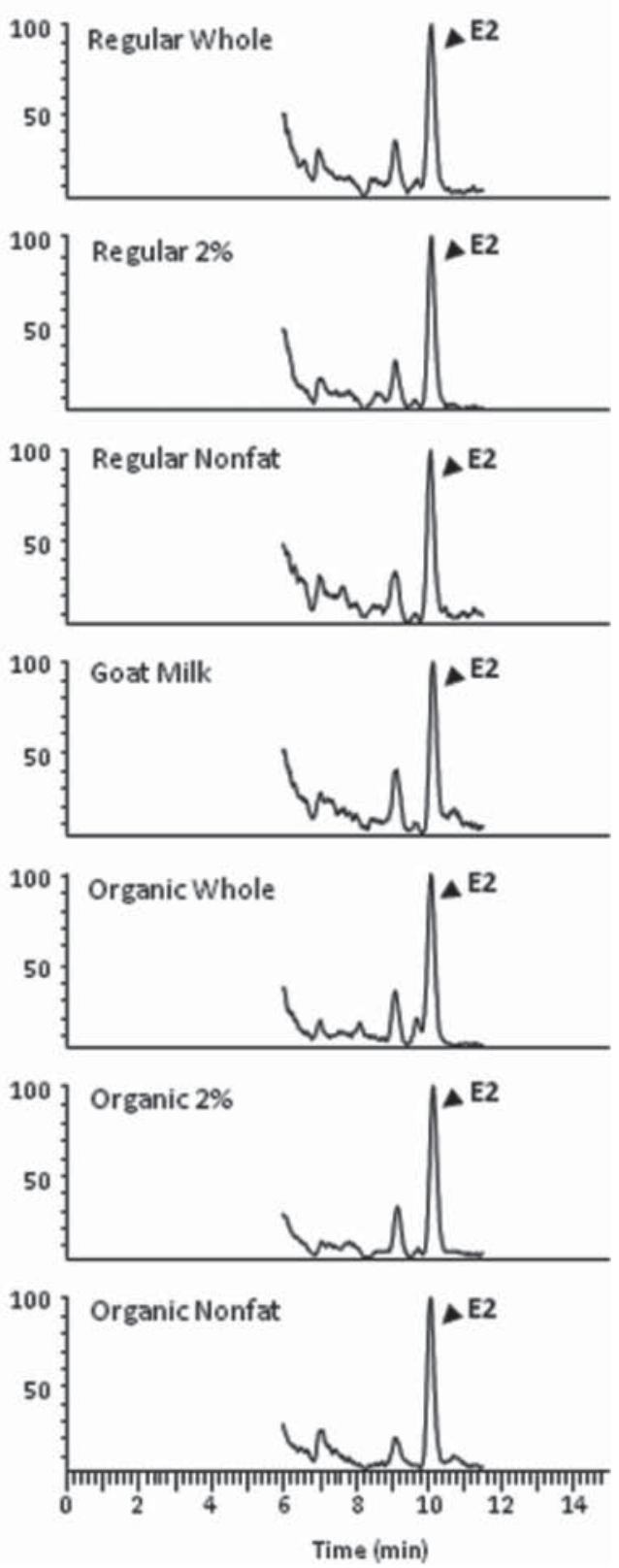

Figure 3. High performance liquid chromatography-tandem mass spectrometry selected reaction monitoring (SRM) chromatographic profiles of $\mathrm{A}$ ) total (unconjugated + conjugated) estrone $\left(\mathrm{E}_{1}\right)$ and $\left.\mathrm{B}\right) 17 \beta$-estradiol $\left(\mathrm{E}_{2}\right)$ in all milk forms analyzed in this study.

sulfated, among others). This result is not surprising, as both $\mathrm{E}_{1}$ and $\mathrm{E}_{2}$ have been previously shown to exist primarily in conjugated forms in human serum $(\mathrm{Xu}$ et al., 2007b). Whereas regular whole and regular $2 \%$ milks contained the highest concentrations of unconjugated $\mathrm{E}_{1}$, organic whole $(260.0 \mathrm{pg} / \mathrm{mL})$ and organic $2 \%(240.5 \mathrm{pg} / \mathrm{mL})$ contained the highest concentration of total $\mathrm{E}_{1}$. In fact, all of the organic milks contained higher concentrations of total $\mathrm{E}_{1}$ than any of the regu- lar milks. Goat milk $(42.8 \mathrm{pg} / \mathrm{mL})$ contained only $33 \%$ of the total $\mathrm{E}_{1}$ compared with any of the other 6 milk products. Similar to the trend observed for $\mathrm{E}_{1}$, the highest concentrations of total $\mathrm{E}_{2}$ were found in organic whole $(61.5 \mathrm{pg} / \mathrm{mL})$, organic $2 \%(52.8 \mathrm{pg} / \mathrm{mL})$, and organic nonfat $(38.0 \mathrm{pg} / \mathrm{mL})$ milks. All of these concentrations were higher than those observed in any of the regular milks $(28.2-31.3 \mathrm{pg} / \mathrm{mL})$. Goat milk contained the lowest concentration of both total $\mathrm{E}_{1}(42.8 \mathrm{pg} / \mathrm{mL})$ 
Table 2. Unconjugated (i.e., free) estrogen concentrations $(\mathrm{pg} / \mathrm{mL})$ of estrone $\left(\mathrm{E}_{1}\right)$ and $17 \beta$-estradiol $\left(\mathrm{E}_{2}\right)$ found in milk (data are expressed as means \pm SD of 12 samples for each form of milk)

\begin{tabular}{|c|c|c|c|c|c|c|c|}
\hline Item & $\begin{array}{l}\text { Regular } \\
\text { whole }\end{array}$ & $\begin{array}{c}\text { Regular } \\
2 \%\end{array}$ & $\begin{array}{c}\text { Regular } \\
\text { nonfat }\end{array}$ & $\begin{array}{c}\text { Organic } \\
\text { whole }\end{array}$ & $\begin{array}{c}\text { Organic } \\
2 \%\end{array}$ & $\begin{array}{c}\text { Organic } \\
\text { nonfat }\end{array}$ & $\begin{array}{l}\text { Regular } \\
\text { goat }\end{array}$ \\
\hline $\mathrm{E}_{1}$ & $14.45 \pm 1.49$ & $13.58 \pm 1.00$ & $5.08 \pm 0.20$ & $9.74 \pm 0.39$ & $11.95 \pm 0.42$ & $4.39 \pm 0.23$ & $1.45 \pm 0.07$ \\
\hline $\mathrm{E}_{2}$ & $5.84 \pm 0.63$ & $2.65 \pm 0.33$ & $0.63 \pm 0.10$ & $6.00 \pm 0.46$ & $2.24 \pm 0.19$ & $0.48 \pm 0.02$ & $1.82 \pm 0.04$ \\
\hline Total & $20.29 \pm 2.12$ & $16.23 \pm 1.33$ & $5.71 \pm 0.30$ & $15.74 \pm 0.85$ & $14.19 \pm 0.61$ & $4.87 \pm 0.25$ & $3.27 \pm 0.11$ \\
\hline
\end{tabular}

and $\mathrm{E}_{2}(17.9 \mathrm{pg} / \mathrm{mL})$. The sum of the concentrations of total $\mathrm{E}_{1}$ and $\mathrm{E}_{2}$ in goat milk was only $38 \%$ of that in any of the cow milk products tested. In fact, the sum of the concentrations of total $\mathrm{E}_{1}$ and $\mathrm{E}_{2}$ in goat milk was less than $20 \%$ of that observed for organic whole milk, which contained the highest combined levels of total $\mathrm{E}_{1}$ and $\mathrm{E}_{2}$.

Organic nonfat $(2.5 \%)$ and goat $(3.4 \%)$ milk contained the lowest percentage of unconjugated compared with total $\mathrm{E}_{1}$ concentrations, whereas regular whole
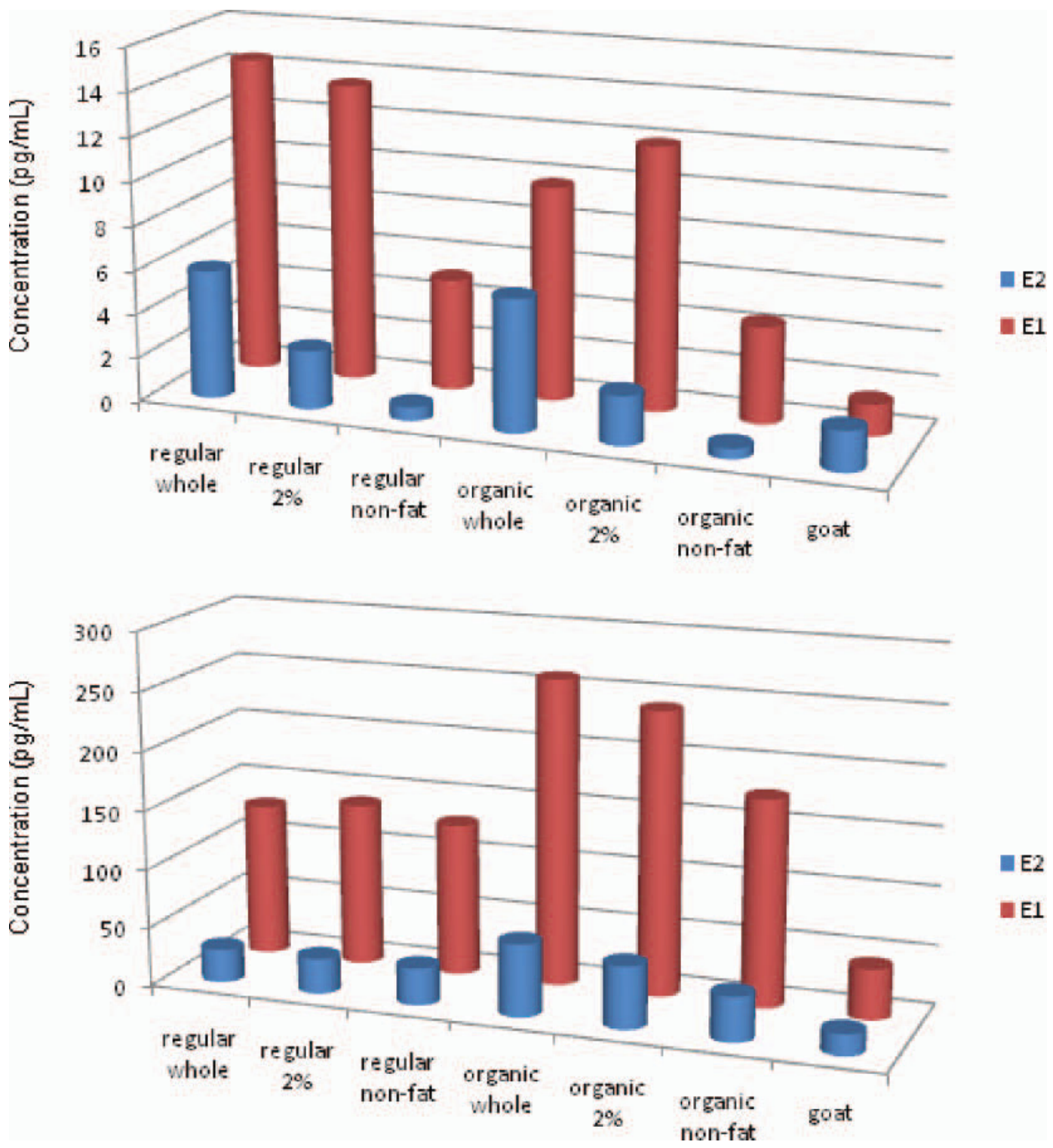

Figure 4. Bar chart showing the absolute levels of A) free (unconjugated) and $\mathrm{B}$ ) total (unconjugated + conjugated) estrone $\left(\mathrm{E}_{1}\right)$ and $17 \beta$-estradiol $\left(\mathrm{E}_{2}\right)$ measured in the milk products analyzed in this study. Color version available in the online PDF. 
Table 3. Unconjugated + conjugated (i.e., total) concentrations $(\mathrm{pg} / \mathrm{mL})$ of estrone $\left(\mathrm{E}_{1}\right)$ and $17 \beta$-estradiol $\left(\mathrm{E}_{2}\right)$ found in milk (data are expressed as means \pm SD of 12 samples for each form of milk)

\begin{tabular}{llllcccc}
\hline Item & \multicolumn{1}{c}{$\begin{array}{c}\text { Regular } \\
\text { whole }\end{array}$} & \multicolumn{1}{c}{$\begin{array}{c}\text { Regular } \\
2 \%\end{array}$} & $\begin{array}{c}\text { Regular } \\
\text { nonfat }\end{array}$ & $\begin{array}{c}\text { Organic } \\
\text { whole }\end{array}$ & $\begin{array}{c}\text { Organic } \\
2 \%\end{array}$ & $\begin{array}{c}\text { Organic } \\
\text { nonfat }\end{array}$ & $\begin{array}{c}\text { Regular } \\
\text { goat }\end{array}$ \\
\hline $\mathrm{E}_{1}$ & $129.9 \pm 18.48$ & $138.7 \pm 22.28$ & $129.2 \pm 17.72$ & $260.0 \pm 28.32$ & $240.5 \pm 22.16$ & $175.4 \pm 34.53$ & $42.78 \pm 4.28$ \\
$\mathrm{E}_{2}$ & $28.19 \pm 5.26$ & $29.57 \pm 5.31$ & $31.28 \pm 3.85$ & $61.52 \pm 11.84$ & $52.82 \pm 6.06$ & $38.02 \pm 6.89$ & $17.87 \pm 2.80$ \\
Total & $158.1 \pm 23.74$ & $168.3 \pm 27.59$ & $160.5 \pm 21.57$ & $321.5 \pm 40.16$ & $293.3 \pm 28.22$ & $213.4 \pm 41.42$ & $60.65 \pm 7.08$ \\
\hline
\end{tabular}

(11.1\%) and regular $2 \%(9.8 \%)$ milk contained the highest percentage. Organic nonfat $(1.3 \%)$ and regular nonfat $(2.0 \%)$ milk contained the lowest percentage of unconjugated compared with total $\mathrm{E}_{2}$ concentrations, whereas regular whole $(20.7 \%)$ and regular goat $(10.2 \%)$ milk contained the highest percentage. The difference between unconjugated and total forms was smallest for regular whole milk and largest for organic nonfat milk, where the data suggest that over $87 \%$ of $\mathrm{E}_{1}$ and $\mathrm{E}_{2}$ in regular whole milk is conjugated, whereas this percentage is over $97 \%$ for organic nonfat milk. On average, the data shows that only about $6 \%$ of $\mathrm{E}_{1}$ and $\mathrm{E}_{2}$ are found in the unconjugated, biologically active forms in the milk products tested.

The rather dramatic decrease in levels of unconjugated $\mathrm{E}_{1}$ and $\mathrm{E}_{2}$ compared with total values from whole and $2 \%$ to nonfat in both regular and organic milks is likely due to the higher aqueous composition of nonfat milks combined with the higher fat solubility of these compounds. In total form, however, all regular cow milks display relatively consistent levels of total $\mathrm{E}_{1}$ plus $\mathrm{E}_{2}$ (ranging from 158.06 to $168.25 \mathrm{pg} / \mathrm{mL}$ ), whereas organic milks were much more inconsistent (ranging from 213.40 to $321.54 \mathrm{pg} / \mathrm{mL}$ ). The total forms of $E_{1}$ and $\mathrm{E}_{2}$ for goat milk were dramatically lower compared with regular and organic milk, with a concentration of $60.65 \mathrm{pg} / \mathrm{mL}$. Total and unconjugated forms of $\mathrm{E}_{1}$ and $\mathrm{E}_{2}$ for all milks forms ranged from 60.65 to $321.54 \mathrm{pg} /$ $\mathrm{mL}$ and 3.27 to $20.29 \mathrm{pg} / \mathrm{mL}$, respectively.

\section{DISCUSSION}

In this study, the concentrations of $\mathrm{E}_{1}$ and $\mathrm{E}_{2}$ were compared between goat milk and 6 commonly consumed cow milk products. The accumulative concentrations of unconjugated and total $\mathrm{E}_{1}$ and $\mathrm{E}_{2}$ were significantly lower in goat milk compared with the cow milks tested. In particular, the total levels of $\mathrm{E}_{1}$ and $\mathrm{E}_{2}$ were no more than $38 \%$ of that contained in any of the cow milks tested. When comparing these steroid hormone levels in goat and cow milk, the obvious question that comes to mind for concerned consumers is which product is safer for consumption. For those concerned with $\mathrm{E}_{1}$ and $\mathrm{E}_{2}$ consumption, the data from this study indicates that goat milk is safer to consume than all forms of regular cow milk. Goat milk is consistently lower in both conjugated and unconjugated estrogens. Another possible point of concern for consumers is the presence of catechol estrogens in milk products. Significant data have been produced to show that catechol estrogens are strong promoters for carcinogenesis, but currently very little literature exists regarding the quantitation of the following catechol estrogens in commercial milk products: 2-hydroxyestrone $\left(2-\mathrm{OHE}_{1}\right), 2$-hydroxyestradiol $\left(2-\mathrm{OHE}_{2}\right)$, and 4-hydroxyestrone (4-OHE $\mathrm{OH}_{1}$; Yager and Davidson, 2006; Farlow et al., 2009). These catechol estrogens are of particular concern because of their highly reactive nature. Although catechol estrogens were not quantitated in this study, based on estrogen metabolisms, their levels would also be lower in goat milk compared with regular milk. This study particularly stressed the importance of quantitating $\mathrm{E}_{1}$ and $\mathrm{E}_{2}$ in goat milk because of the following: 1) no study has attempted (to the best of our knowledge) to quantitate $\mathrm{E}_{1}$ and $\mathrm{E}_{2}$ in the most commonly consumed milk in the world (goat milk) and 2) $\mathrm{E}_{1}$ and $\mathrm{E}_{2}$ are the most common estrogen metabolites and are the precursors from which other estrogen metabolites are derived, including $2-\mathrm{OHE}_{1}, 2-\mathrm{OHE}_{2}$, and $4-\mathrm{OHE}_{1}$.

Although the main focus of this article was to provide an objective comparison describing the $\mathrm{E}_{1}$ and $\mathrm{E}_{2}$ concentrations in goat and regular cow milk, it is also useful to examine their content in organic cow milks due to their increasing popularity as healthy food alternatives. As seen in Tables 2 and 3, all organic milks were lower in the biologically active, unconjugated $\mathrm{E}_{1}$ and $\mathrm{E}_{2}$ and higher in total concentrations of each when compared directly to their regular milk counterparts. This fact is significant according to a previous study that suggested that the half-lives of conjugated estrogens are longer than those of nonconjugated estrogens due to first mass metabolism in the liver (Schindler et al., 1982). Also significant is the fact that goat milk is lower in unconjugated and total $\mathrm{E}_{1}$ and $\mathrm{E}_{2}$ than all other forms of regular and organic milks. These results show that goat milk has less biologically active EM and shorter half-lives for its conjugated estrogens than all other milk forms tested in this study.

Comparing the conjugated $\mathrm{E}_{1}$ and $\mathrm{E}_{2}$ concentrations found in the milk products analyzed in this study to 
Table 4. Ratio of conjugated estrone $\left(\mathrm{E}_{1}\right)$ and $17 \beta$-estradiol $\left(\mathrm{E}_{2}\right)$ concentrations ingested from low- and regular-dose hormone replacement therapy (Premarin) to levels in milk products analyzed in this study ${ }^{1}$

\begin{tabular}{|c|c|c|c|c|c|c|c|}
\hline Item & $\begin{array}{l}\text { Regular } \\
\text { whole }\end{array}$ & $\begin{array}{l}\text { Regular } \\
2 \%\end{array}$ & $\begin{array}{c}\text { Regular } \\
\text { nonfat }\end{array}$ & $\begin{array}{l}\text { Organic } \\
\text { nonfat }\end{array}$ & $\begin{array}{l}\text { Organic } \\
\text { whole }\end{array}$ & $\begin{array}{l}\text { Organic } \\
2 \%\end{array}$ & $\begin{array}{l}\text { Goat } \\
\text { milk }\end{array}$ \\
\hline $\begin{array}{l}\text { Conjugated } \mathrm{E}_{1}+\mathrm{E}_{2} \\
(\mathrm{pg} / \mathrm{mL})\end{array}$ & $137.8 \pm 21.62$ & $152.0 \pm 26.26$ & $154.7 \pm 21.27$ & $208.5 \pm 41.17$ & $305.8 \pm 39.31$ & $279.1 \pm 27.61$ & $57.38 \pm 6.97$ \\
\hline $\begin{array}{l}\text { Regular-dose Premarin } \\
\qquad\left(\mathrm{E}_{1}+\mathrm{E}_{2}\right)\end{array}$ & 4,537 & 4,111 & 4,039 & 2,997 & 2,043 & 2,239 & 10,892 \\
\hline
\end{tabular}

${ }^{1}$ The projected amount of $\mathrm{E}_{1}$ and $\mathrm{E}_{2}$ consumed daily by the average resident of the United States is also shown for each type of milk.

${ }^{2}$ The average daily intakes are based on statistics provided at http://www.ars.usda.gov/SP2UserFiles/Place/12355000/pdf/DBrief/fluid milk_0506.pdf for individuals greater than $2 \mathrm{yr}$ of age and the mean values of $\mathrm{E}_{1}$ and $\mathrm{E}_{2}$ found in each milk product.

those administered during hormone therapy is useful for individuals concerned about estrogen intake via dietary consumption. A previous study showed that conjugated estrogen metabolite concentrations in several commercial milk products, mostly regular milk, were low compared with the conjugated equine estrogens in low-dose $(300 \mu \mathrm{g})$ and regular-dose $(625 \mu \mathrm{g})$ Premarin (Farlow et al., 2009). Premarin is a hormone replacement therapy that is associated with breast cancer incidence in post-menopausal women after long-term exposure (Beral, 2003; Chen et al., 2006). The level of conjugated estrogen metabolites in $1 \mathrm{~L}$ of skim milk was approximately $0.15 \%$ of the amount of conjugated $\mathrm{E}_{1}$ and $\mathrm{E}_{2}$ administered through low-dose Premarin and only $0.07 \%$ of that obtained through a regular dose.

Similarly, in this study, conjugated $\mathrm{E}_{1}$ and $\mathrm{E}_{2}$ concentrations were quite low for all milk types, particularly goat milk. The ratios of conjugated $\mathrm{E}_{1}$ and $\mathrm{E}_{2}$ compared with those found in low and regular doses of Premarin are provided in Table 4 for all types of milk products analyzed in this study. Conjugated steroid hormone values were determined by subtracting the unconjugated values from the total values presented for $\mathrm{E}_{1}$ and $\mathrm{E}_{2}$ in Tables 2 and 3, respectively. The data presented in Table 4 clearly indicates that all milk forms are significantly lower in conjugated EM concentration than those administered by Premarin for hormone replacement therapy. Although this indication may seem rather obvious, it nevertheless provides consumers with useful baseline values with which to compare milk products. The great difference regarding conjugated $\mathrm{E}_{1}$ and $\mathrm{E}_{2}$ concentrations between low-, regular-dose Premarin and commercially available milk products should provide consumers concerned about EM in milk products with relative comfort; however, no definitive conclusions may be made about safety regarding steroid hormone consumption via commercial milk products because the effect of long-term ingestion at these levels is presently unknown (Zhou et al., 2007; Martini and Wood, 2009).

The average daily intake of $\mathrm{E}_{1}$ and $\mathrm{E}_{2}$ that would be consumed by the average US resident over the age of 2 yr is also provided in Table 4 . The average daily intake is based on the findings reported by the USDA for the years 2005 to 2006 (http://www.ars.usda.gov/SP2UserFiles/Place/12355000/pdf/DBrief/fluid_milk_0506.

pdf). In this study, individuals (both males and females) over the age of 2 were reported to consume slightly more than $3 / 4$ cup of fluid milk per day. Converting this volume to $178 \mathrm{~mL}$ and multiplying by the mean levels of $E_{1}$ and $E_{2}$ found in the various milk products provides an estimate of the estrogen levels that would be consumed daily if an individual drunk exclusively one type of milk. The values range from 10.2 to 54.4 ng from goat to organic whole milk, respectively. The daily intake of $\mathrm{E}_{1}$ and $\mathrm{E}_{2}$ consumed through goat milk is less than $42 \%$ of that ingested via regular whole milk, which contains the next lowest estrogen levels. To put these values into proper perspective, the data shows that the average American consumes less than 0.02\% of the amount of estrogens through fluid milk than is ingested by an individual taking low-dose Premarin (i.e., $300 \mu \mathrm{g}$ ).

\section{CONCLUSIONS}

This study compared the unconjugated and total $\mathrm{E}_{1}$ and $\mathrm{E}_{2}$ concentrations in goat and cow milks (both regular and organic). The combined levels of these estrogen metabolites were significantly lower in goat milk; however, the differences between regular and organic cow milks were not as significant. Although the doses of either $\mathrm{E}_{1}$ or $\mathrm{E}_{2}$ were small compared with what would be ingested from taking Premarin, the cumulative effects of years of consumption are still unknown. Given the surprisingly low concentrations of conjugated and 
unconjugated $\mathrm{E}_{1}$ and $\mathrm{E}_{2}$ in regular goat milk, this milk would be a healthy dietary alternative for individuals concerned with steroid hormone consumption. We are currently trying to 1) quantitate the level of estrone sulfate in all of the milk forms used in this study to provide more support and confirmation for our initial findings and 2) refine our method to quantitate other EM derivatives of $\mathrm{E}_{1}$ and $\mathrm{E}_{2}$ in all milk forms analyzed in this study, including various catechol estrogens.

\section{ACKNOWLEDGMENTS}

This project has been funded in whole or in part with Federal funds from the National Cancer Institute, National Institutes of Health (Bethesda, MD), under Contract HHSN261200800001E.

\section{REFERENCES}

Beral, V. 2003. Breast cancer and hormone-replacement therapy in the Million Women Study. Lancet 362:419-427.

Bernstein, L., and R. K. Ross. 1993. Endogenous hormones and breast cancer risk. Epidemiol. Rev. 15:48-65.

Chen, W. Y., J. E. Manson, S. E. Hankinson, B. Rosner, M. D. Holmes, W. C. Willett, and G. A. Colditz. 2006. Unopposed estrogen therapy and the risk of invasive breast cancer. Arch. Intern. Med. 166:1027-1032.

Coila, B. 2010. Is goat's milk healthy? Accessed Aug. 15, 2011. http:// www.livestrong.com/article/336633-is-goats-milk-healthy.

Courant, F., J.-P. Antignac, J. Laille, F. Monteau, F. Andre, and B. Le Bizec. 2008. Exposure assessment of prepubertal children to steroid endocrine disruptors. 2. Determination of steroid hormones in milk, egg, and meat samples. J. Agric. Food Chem. $56: 3176-3184$

Dias, A., A. Santos, and J. A. Pinheiro. 2010. Persistence of cow's milk allergy beyond two years of age. Allergol. Immunopathol. (Madr.) 38:8-12.

Farlow, D. W., X. Xu, and T. D. Veenstra. 2009. Quantitative measurement of endogenous estrogen metabolites, risk-factors for development of breast cancer, in commercial milk products by LCMS/MS. J. Chromatogr. B Analyt. Technol. Biomed. Life Sci. 877:1327-1334.

Ganmaa, D., and A. Sato. 2005. The possible role of female sex hormones in milk from pregnant cows in the development of breast, ovarian and corpus uteri cancers. Med. Hypotheses 65:1028-1037.
Haenlein, G. F. W. 2001. Past, present, and future perspectives of small ruminant dairy research. J. Dairy Sci. 84:2097-2115.

Haenlein, G. F. W. 2004. Goat milk in human nutrition. Small Rumin. Res. 51:155-163.

Larsson, S. C., L. Bergkvist, and A. Wolk. 2004. Milk and lactose intakes and ovarian cancer risk in the Swedish mammography cohort. Am. J. Clin. Nutr. 80:1353-1357.

Liehr, J. G. 2000. Is estradiol a genotoxic mutagenic carcinogen? Endocr. Rev. 21:40-54

Martini, L. A., and R. J. Wood. 2009. Milk intake and the risk of type 2 diabetes mellitus, hypertension and prostate cancer. Arq. Bras. Endocrinol. Metabol. 53:688-694.

Qin, L. Q., P. Y. Wang, T. Kaneko, K. Hoshi, and A. Sato. 2004. Estrogen: One of the risk factors in milk for prostate cancer. Med. Hypotheses 62:133-142.

Savilahti, E. M., V. Rantanen, J. S. Lin, S. Karinen, K. M. Saarinen, M. Goldis, M. J. Mäkelä, S. Hautaniemi, E. Savilahti, and H. A Sampson. 2010. Early recovery from cow's milk allergy is associated with decreasing IgE and increasing IgG4 binding to cow's milk epitopes. J. Allergy Clin. Immunol. 125:1315-1321.

Schindler, A. E., H. M. Bolt, M. Zwirner, G. Hochlehnert, and R. Göser. 1982. Comparative pharmacokinetics of oestradiol, oestrone, oestrone sulfate and "conjugated oestrogens" after oral administration. Arzneimittelforschung 32:787-791.

Solinas, C., M. Corpino, R. Maccioni, and U. Pelosi. 2010. Cow's milk protein allergy. J. Matern. Fetal Neonatal Med. 23(Suppl 3):76-79.

Willett, W. 2003. Lessons from dietary studies in Adventists and questions for the future. Am. J. Clin. Nutr. 78:539S-543S.

Xu, X., L. K. Keefer, R. G. Ziegler, and T. D. Veenstra. 2007a. A liquid chromatography-mass spectrometry method for the quantitative analysis of urinary endogenous estrogen metabolites. Nat. Protoc. 2:1350-1355.

Xu, X., J. M. Roman, H. J. Issaq, L. K. Keefer, T. D. Veenstra, and R. G. Ziegler. 2007b. Quantitative measurement of endogenous estrogens and estrogen metabolites in human serum by liquid chromatography-tandem mass spectrometry. Anal. Chem. 79:7813-7821.

Xu, X., T. D. Veenstra, S. Fox, J. M. Roman, H. J. Issaq, R. Falk, J. E. Saavedra, L. K. Keefer, and R. G. Ziegler. 2005. Measuring fifteen endogenous estrogens simultaneously in human urine by high performance liquid chromatography-mass spectrometry. Anal. Chem. $77: 6646-6654$

Yager, J. D., and N. E. Davidson. 2006. Estrogen carcinogenesis in breast cancer. N. Engl. J. Med. 354:270-282.

Zhou, H., L.-Q. Qin, F.-L. Tang, D.-F. Ma, P.-Y. Wang, and Y. Wang. 2007. Effect of milk on the 7,12-dimethylbenz[a]-anthraceneinduced mammary tumor model in rat. Food Chem. Toxicol. $45: 1868-1872$ 